INRA, Prod. Anim., 2005, 18 (2), 131-141

\section{Canards de Barbarie, Pékin et leurs hybrides : aptitude à l'engraissement}

\begin{abstract}
E. BAEZA ${ }^{1}$, N. RIDEAU 1 , P. CHARTRIN ${ }^{1}$, S. DAVAIL 2 , R. HOO-PARIS 2 , J. MOUROT ${ }^{3}$,

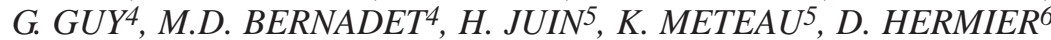

1 INRA Tours, Station de Recherches Avicoles, F-37380 Nouzilly

2 IUT des Pays de l'Adour, Laboratoire de Nutrition et Biologie Appliquée, F-40000 Mont de Marsan

${ }^{3}$ INRA, UMR, Systèmes d'Elevage Nutrition Animale et Humaine, F-35590 St Gilles

${ }^{4}$ INRA Artiguères, Unité Expérimentale des Palmipèdes à Foie Gras, F-40280 Benquet ${ }^{5}$ INRA Le Magneraud, Unité Expérimentale sur l'Elevage Alternatif et la Santé des Monogastriques, F-17700 St Pierre d'Amilly ${ }^{6}$ INAPG, UMR Physiologie de la Nutrition et du Comportement Alimentaire, F-75005 Paris

Courriel : baeza@tours.inra.fr
\end{abstract}

\begin{abstract}
Parmi les différents types de canard qui existent, seuls le canard de Barbarie et le canard mulard (résultat du croisement entre un mâle Barbarie et une femelle commune, (le plus souvent Pékin) sont utilisés pour produire du foie gras. Quels sont les mécanismes métaboliques et physiologiques qui leur confèrent cette aptitude ? Quelles en sont les répercussions sur les caractéristiques du foie gras et de la viande ?
\end{abstract}

En 2003, l’offre française en foie gras cru a atteint 16437 tonnes dont $96 \%$ issues du canard (OFIVAL 2004). Une part importante de la production de viande de canard (237 500 tec en 2003) est donc liée à la commercialisation du foie gras (50\% du volume en 2003, OFIVAL 2004). En France, les espèces les plus utilisées sont les canards mulards et Barbarie. À 8, 10 et 12 semaines, le canard de Barbarie présente un poids vif à l'abattage et des rendements en viande supérieurs à ceux des canards Pékin et mulard (figure 1, Ricard 1986). Il est donc principalement utilisé pour la production de canard à rôtir (vente en carcasses entières) et de viande (vente de morceaux de découpe). Le canard mulard est issu du croisement entre un mâle Barbarie (Cairina moschata) et une femelle commune généralement Pékin (Anas plathyrynchos). Il bénéficie d'un effet d'hétérosis pour la capacité d'ingestion et la production de foie gras (consommation alimentaire et poids de foie gras supérieurs à la moyenne des espèces parentales) et le taux de fonte en pasteurisation ou stérilisation de son foie gras est faible (Guy et al 1995). Il est donc majoritairement utilisé pour la production de foie gras en France : $97 \%$ des canetons mis en place pour la production de foie gras en 2002 d'après le Comité Interprofessionnel du Foie Gras (CIFOG). Pourtant, en production de canards maigres, le canard mulard présente des quantités de gras abdominal et de gras sous-cutané inférieures à celles des espèces parentales (figure 1, Ricard 1986). Le dépôt de lipides souscutanés est plus important chez les canards Pékin et la quantité de gras abdominal est plus importante chez le canard de Barbarie. L'aptitude à l'engraissement et la répartition des dépôts de lipides varient donc largement selon les génotypes. Après un bref rappel sur les mécanismes mis en œuvre lors du gavage des palmipèdes, nous montrerons à quel niveau les génotypes diffèrent et nous en analyserons les conséquences pour la production et la qualité du foie gras et de la viande.

\section{1 / Stéatose hépatique chez les palmipèdes}

Au cours du gavage, les palmipèdes sont essentiellement nourris avec du maïs, matière première riche en amidon (60 \%) et en lipides (4 \%). Après hydrolyse des aliments au niveau du tube digestif et absorption, les lipides sont transportés par sang portal grâce aux portomicrons jusqu'au foie ainsi que de grandes quantités de glucose (figure 2, Hermier et al 1999a, Davail et al 2003). Il s'ensuit une intense lipogénèse hépatique. Les triglycérides néo-synthétisés incorporés dans les lipoprotéines, en particulier les VLDL (Very Low Density Lipoproteins) sont secrétés et transportés vers les tissus périphériques. Lorsque la capacité de lipogénèse induite par le gavage dépasse la capacité de synthèse et de sécrétion des VLDL, les triglycérides néo-synthétisés s’accumulent dans les hépatocytes. Le gavage induit aussi un engraissement important des tissus périphériques comme les tissus adipeux et les muscles. Les lipides stockés dans ces tissus proviennent des lipides alimentaires transportés par des lipoprotéines intestinales (portomicrons) et des lipides synthétisés dans le foie et transportés essentiellement par les VLDL. Grâce à l'hydrolyse des triglycérides des lipoprotéines par la lipoprotéine lipase (LPL), les tissus périphé- 
Figure 1. Rendement en muscles et engraissement des canards de Barbarie, Pékin et mulard abattus à 8,10 ou 12 semaines ( $n=10$, Ricard 1986).

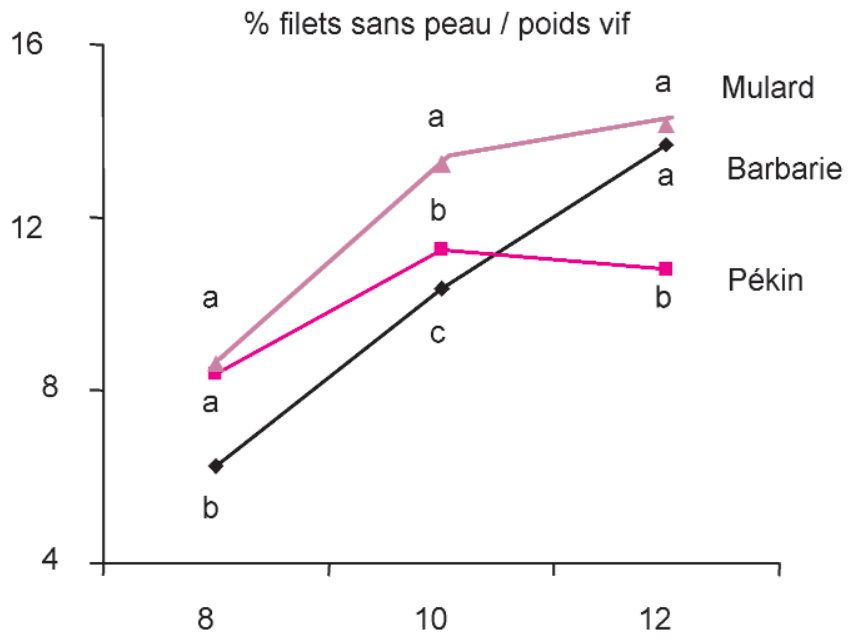

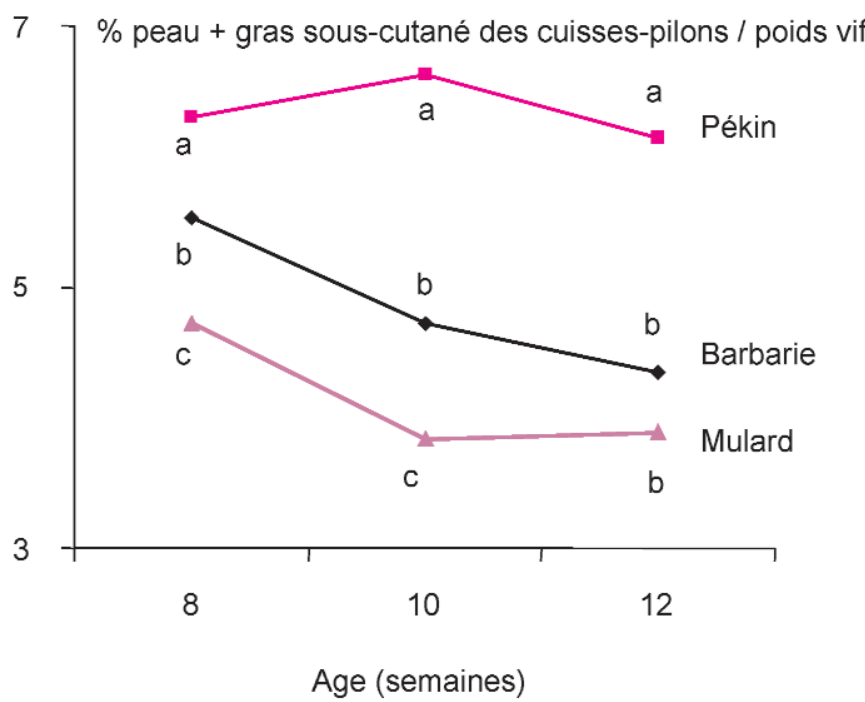

riques vont pouvoir capter les lipides circulants. Les triglycérides non hydrolysés vont retourner au foie et contribuer à la stéatose hépatique (figure 2, Hermier et al 1999a, Davail et al 2003).

\section{2 / Croissance et consom- mation alimentaire}

Au cours de la période d’élevage, les canards de Barbarie ont une efficacité alimentaire supérieure à celle des autres génotypes et les canards Pékin ont l'Indice de Consommation (IC) le plus élevé (tableau 1, Chartrin et al 2003). En comparant les performances des canards mulards et Barbarie élevés jusqu'à l'âge de 84 jours, Guy et al (1995) avaient obtenu respectivement des IC de 4,37 et 3,24. Pour des canards Pékin, mulards et Barbarie élevés jusqu’à 91 jours, les IC étaient respectivement de 4,41, 4,08 et 3,22 (Guy et al 1999). La comparaison de

Tableau 1. Effet du génotype sur I'Indice de Consommation (IC) au cours de la période d'élevage (0 à 84 jours), la consommation totale d'équivalent maïs sec au cours de la période de gavage (85 à 98 jours) et la consommation totale d'aliment croissance des canards témoins nourris ad libitum de 85 à 98 jours ( $n=1$, Chartrin et al 2003).

\begin{tabular}{|l|c|c|c|c|}
\hline \multicolumn{1}{|c|}{ Génotypes } & Barbarie & Hinny & Mulard & Pékin \\
\hline $\begin{array}{l}\text { IC en période d'élevage } \\
\text { Consommation d'aliment } \\
\text { gavage (g) }\end{array}$ & 2,76 & 3,23 & 3,29 & 3,63 \\
$\begin{array}{l}\text { Consommation d'aliment } \\
\text { des canards témoins (g) }\end{array}$ & 3219 & 10341 & 10552 & 9674 \\
\hline
\end{tabular}

a \% muscles cuisses-pilons / poids vif

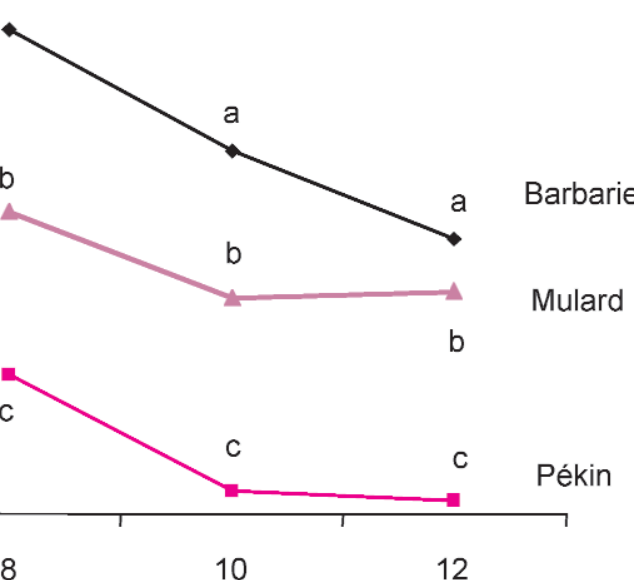

$\%$ gras abdominal / poids vif

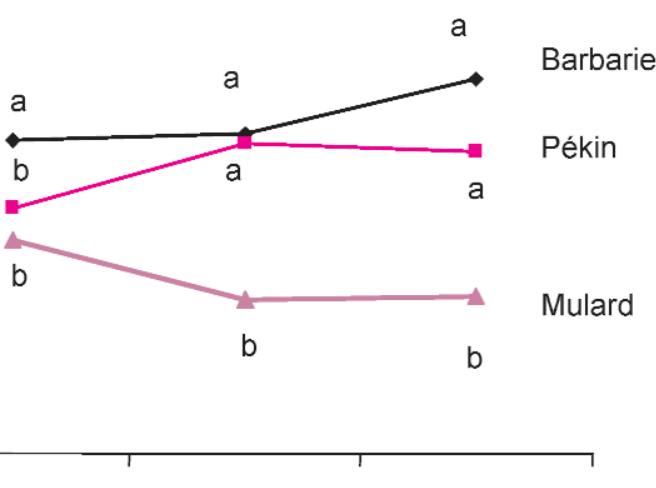

8 10

12 deux lignées de poulets sélectionnées de façon divergente sur la quantité de gras abdominal montre que l'IC est inférieur chez les poulets génétiquement maigres (Alleman et al 1999). Ces observations, réalisées chez le poulet et le canard, suggèrent qu'une bonne efficacité alimentaire est associée à un faible engraissement périphérique.

Au cours de la période de gavage, la capacité d'ingestion des canards mulards est la plus importante et celle des canards de Barbarie la plus faible (tableau 1, Chartrin et al 2003). En comparant des canards mulards et Barbarie gavés pendant 13 jours, Guy et al (1995) avaient mesuré une consommation de 10,7 et $8,1 \mathrm{~kg}$ d’équivalent maïs sec. Pour des canards Pékin, mulards et Barbarie gavés pendant 14 jours, ces quantités s'élevaient respectivement à 7,1, 9,6 et $7,2 \mathrm{~kg}$ d'équivalent maïs sec (Guy et al 1999). 
Figure 2. Mécanismes de la stéatose hépatique chez les palmipèdes (Hermier et al 1999) et aptitude au gavage des canards de Barbarie (B), Pékin (P), mulard $(M)$ et hinny $(H)$.

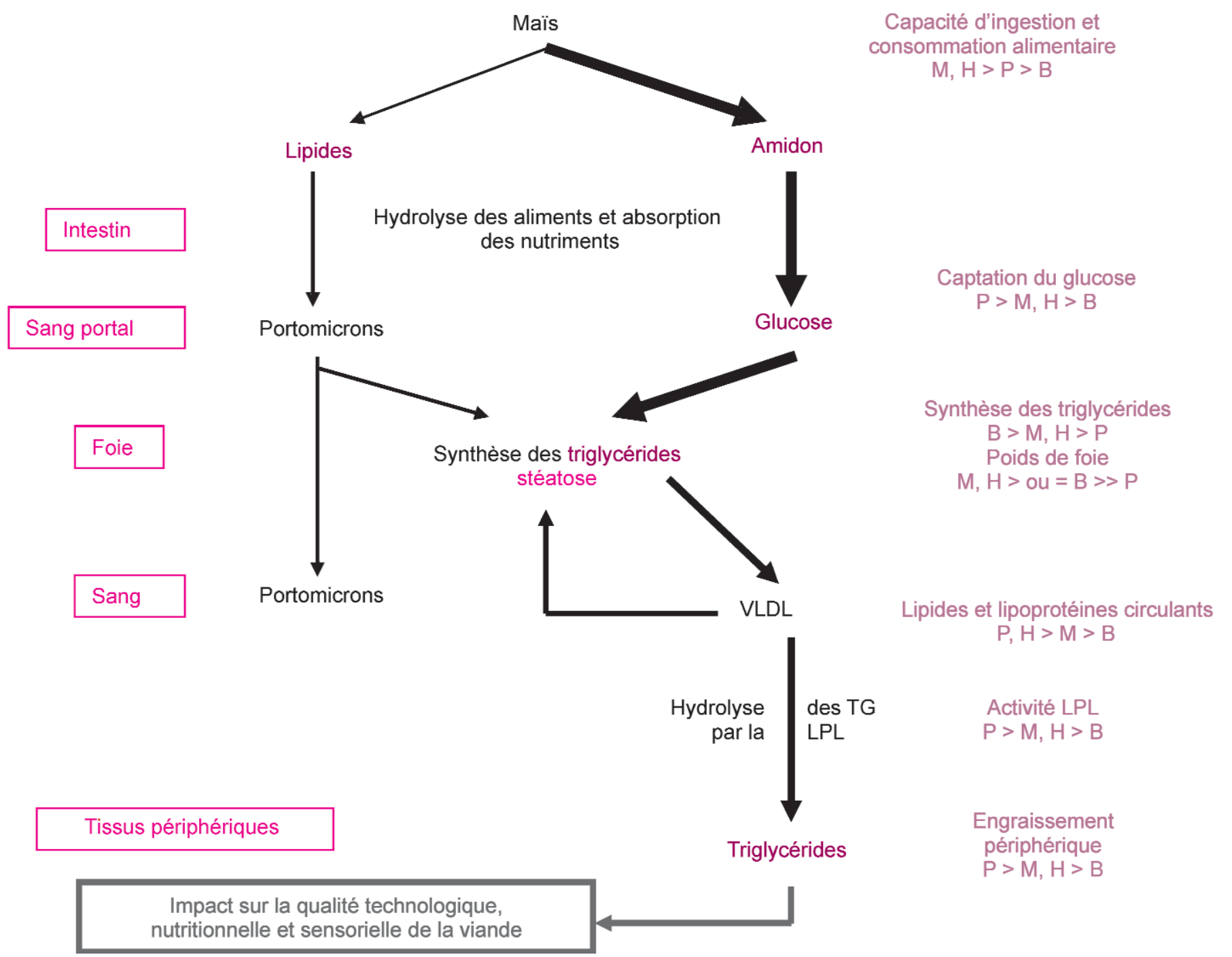

Tableau 2. Effet du génotype sur l'évolution du poids vif (PV en g) au cours de la période d'élevage des canards (moyenne $\pm E T, n=50$, Chartrin et al 2003).

\begin{tabular}{|l|c|c|c|c}
\hline \multicolumn{1}{c|}{ Génotypes } & Barbarie & Hinny & Mulard & Pékin \\
\hline PV à 4 semaines & $1257 \pm 92 \mathrm{~d}$ & $1593 \pm 85 \mathrm{c}$ & $1684 \pm 115 \mathrm{~b}$ & $1741 \pm 124 \mathrm{a}$ \\
PV à 6 semaines & $2715 \pm 148 \mathrm{c}$ & $2626 \pm 148 \mathrm{~d}$ & $2846 \pm 209 \mathrm{~b}$ & $2985 \pm 183 \mathrm{a}$ \\
PV à 12 semaines & $4919 \pm 323 \mathrm{a}$ & $4588 \pm 395 \mathrm{~b}$ & $4622 \pm 314 \mathrm{~b}$ & $4477 \pm 294 \mathrm{~b}$ \\
\hline
\end{tabular}

a - d : Effet significatif du génotype pour un paramètre donné avec $P<0,05$.

Tableau 3. Effet du génotype sur les rendements à l'abattage de canards gavés âgés de 14 semaines (moyenne $\pm E T, n=25$ ).

\begin{tabular}{|l|c|c|c|c|}
\hline \multicolumn{1}{|c|}{ Génotypes } & Barbarie & Hinny & Mulard & Pékin \\
\hline Poids vif $(\mathrm{g})$ & $6495 \pm 262 \mathrm{a}$ & $6345 \pm 339 \mathrm{ab}$ & $6488 \pm 296 \mathrm{a}$ & $6195 \pm 270 \mathrm{~b}$ \\
Poids carcasse $(\mathrm{g})$ & $5381 \pm 223$ & $5369 \pm 296$ & $5492 \pm 243$ & $5339 \pm 257$ \\
Poids paletot $(\mathrm{g})$ & $2700 \pm 169$ & $2722 \pm 241$ & $2810 \pm 175$ & $2824 \pm 220$ \\
Poids foie $(\mathrm{g})$ & $503 \pm 74 \mathrm{a}$ & $525 \pm 78 \mathrm{a}$ & $531 \pm 104 \mathrm{a}$ & $355 \pm 108 \mathrm{~b}$ \\
\hline
\end{tabular}

$a-b$ : Effet significatif du génotype pour un paramètre donné avec $P<0,05$.

Du fait d'un développement corporel plus tardif, le canard de Barbarie présente le poids vif à 28 jours le plus faible mais le poids vif le plus important à 84 et 96 jours que les animaux aient été gavés ou non (tableaux 2 et 3, Chartrin et al 2003), ce qui confirme les observations préalables de Guy et al (1995, 1999) et Larzul et al (2002).

\section{3 / Composition corporelle}

Le canard Pékin, maigre ou gavé, présente le poids de foie et les poids ou les proportions de muscles les plus faibles et le canard de Barbarie, maigre ou gavé, les poids ou les proportions de muscles les plus importants (tableaux 3 et 4, Chartrin et al 2003) ce qui confirme les observations préalables de Guy et al (1995, 1999), Retailleau (1999) et Larzul et al (2002). Une comparaison de canards Pékin et Barbarie à la mise en pré-gavage à l'âge de 11,5 semaines avait montré que les pourcentages de gras abdominal par rapport au poids vif étaient équivalents (2,26 et 2,23\%) ; en revanche, les canards Pékin avaient un engraissement sous-cutané plus important (1,92 vs 1,33 \% pour la peau des filets, Hermier et al 2003). En fin de gavage, à l'âge de 15 semaines, les canards Pékin présentaient plus de gras abdominal (4,03 vs 3,62 \%) et d'en- 
Tableau 4. Effet du génotype et du gavage sur le poids vif, le poids du foie, du gras abdominal et du Pectoralis major (PM) de canards âgés de 14 semaines ( $G$ = gavés, $T=$ témoins, moyenne $\pm E T, n=8$, Chartrin et al 2003).

\begin{tabular}{|c|c|c|c|c|c|c|c|c|}
\hline \multicolumn{2}{|l|}{ Génotypes } & Barbarie & Hinny & Mulard & Pékin & $\begin{array}{l}\text { Effet du } \\
\text { génotype }\end{array}$ & $\begin{array}{l}\text { Effet du } \\
\text { gavage }\end{array}$ & Interaction \\
\hline Poids vif $(\mathrm{g})$ & $\begin{array}{l}G \\
T\end{array}$ & $\begin{array}{l}6393 \pm 441 a \\
5418 \pm 245 b\end{array}$ & $\begin{array}{l}6315 \pm 402 a \\
4854 \pm 497 c\end{array}$ & $\begin{array}{l}6473 \pm 351 a \\
4455 \pm 392 c\end{array}$ & $\begin{array}{l}5999 \pm 353 a \\
4623 \pm 426 c\end{array}$ & $* \star *$ & $* * *$ & ** \\
\hline Foie $(g)$ & $\begin{array}{l}G \\
T\end{array}$ & $\begin{array}{c}467 \pm 90 a \\
77 \pm 7 c\end{array}$ & $\begin{array}{c}495 \pm 85 a \\
61 \pm 6 c\end{array}$ & $\begin{array}{c}494 \pm 97 a \\
61 \pm 13 c\end{array}$ & $\begin{array}{c}318 \pm 75 b \\
56 \pm 11 c\end{array}$ & $\star \star * \star$ & $* \star *$ & $* * *$ \\
\hline Gras abdominal $(\mathrm{g})$ & $\begin{array}{l}\mathrm{G} \\
\mathrm{T}\end{array}$ & $\begin{array}{l}220 \pm 23 \\
109 \pm 20\end{array}$ & $\begin{array}{l}256 \pm 27 \\
107 \pm 35\end{array}$ & $\begin{array}{c}224 \pm 42 \\
73 \pm 35\end{array}$ & $\begin{array}{l}265 \pm 22 \\
155 \pm 29\end{array}$ & $* * *$ & $* * *$ & ns \\
\hline $\mathrm{PM}(\mathrm{g})$ & $\begin{array}{l}G \\
T\end{array}$ & $\begin{array}{l}408 \pm 49 \\
398 \pm 39\end{array}$ & $\begin{array}{l}290 \pm 25 \\
297 \pm 29\end{array}$ & $\begin{array}{l}309 \pm 28 \\
278 \pm 30\end{array}$ & $\begin{array}{l}208 \pm 33 \\
216 \pm 18\end{array}$ & $\star \star * *$ & ns & ns \\
\hline
\end{tabular}

${ }^{*},{ }^{* *},{ }^{* * *}$ : Effet significatif avec $\mathrm{P}<0,05,0,01,0,001-\mathrm{ns}=$ non significatif

$a-c$ : Différence significative entre lots pour un paramètre donné.

graissement sous-cutané (2,90 vs $1,82 \%)$ que les canards de Barbarie. Lorsque les canards sont gavés en ajustant leur ingéré alimentaire à leur poids vif, les canards Pékin présentent toujours l'engraissement sous-cutané et abdominal le plus important (Davail et al 2003). Chez les oies polonaises qui présentent une faible aptitude à produire du foie gras, par comparaison avec les oies landaises (485 vs 1005 g, Hermier et al 1999a), les différences d'engraissement périphérique sont moindres (523 g vs 411 g de gras abdominal, 161 vs 142 g de gras sous-cutané, 5,4 vs 5,8 g de lipides totaux pour $100 \mathrm{~g}$ de filet ; Hermier et al 1999a, Mourot et al 2000, Davail et al 2000). Par contre le rendement en muscles est supérieur chez les oies polo- naises (6,6 vs 5,4 \% pour le rendement en filets par rapport au poids vif, Hermier et al 1999a).

Lorsque les canards des différents génotypes sont gavés en suivant leur capacité maximale d'ingestion, les canards mulards présentent des poids de foie équivalents voire supérieurs à ceux des canards de Barbarie (Guy et al 1995, 1999, Chartrin et al 2003). Lorsque les canards sont gavés en ajustant leur ingéré alimentaire à leur poids vif, les canards de Barbarie ont des poids de foie supérieurs à ceux des autres génotypes : 585 vs 218 et 152 g pour les canards mulards et Pékin (Davail et al 2003). Ce résultat suggère que la capacité de production de foie

Tableau 5. Effet du génotype sur l'activité (UI/mg protéines) des principales enzymes de la lipogénèse dans le foie de canards âgés de 13 semaines, sacrifiés après leur premier repas de gavage (moyenne $\pm E T, n=10$ ).

\begin{tabular}{|l|cc|c|}
\hline \multicolumn{1}{|c|}{ Génotypes } & Barbarie & Mulard & Pékin \\
\hline Foie $(\mathrm{g})$ & $123 \pm 12 \mathrm{a}$ & $86 \pm 9 \mathrm{~b}$ & $77 \pm 11 \mathrm{~b}$ \\
ACX & $0,70 \pm 0,23 \mathrm{ab}$ & $0,81 \pm 0,33 \mathrm{a}$ & $0,46 \pm 0,19 \mathrm{~b}$ \\
FAS & $56 \pm 25 \mathrm{a}$ & $14 \pm 5 \mathrm{~b}$ & $19 \pm 7 \mathrm{~b}$ \\
G6PDH & $1,17 \pm 0,38 \mathrm{~b}$ & $1,39 \pm 0,36 \mathrm{~b}$ & $2,24 \pm 0,61 \mathrm{a}$ \\
EM & $1,16 \pm 0,22 \mathrm{~b}$ & $1,18 \pm 0,21 \mathrm{ab}$ & $1,46 \pm 0,30 \mathrm{a}$ \\
\hline
\end{tabular}

$a-b$ : Effet significatif du génotype pour un paramètre donné avec $\mathrm{P}<0,05$.

ACX = acétyl CoA carboxylase, EM = enzyme malique, G6PDH = glucose-6-phosphate déshydrogénase, FAS = fatty acid synthase. canards âgés de 14 semaines, sacrifiés plus de $12 \mathrm{~h}$ après leur dernier repas ( $G=$ gavés, $T=$ témoins, moyenne $\pm E T, n=8$ ).

\begin{tabular}{|c|c|c|c|c|c|c|c|c|}
\hline \multicolumn{2}{|c|}{ Génotypes } & Barbarie & Hinny & Mulard & Pékin & $\begin{array}{l}\text { Effet du } \\
\text { génotype }\end{array}$ & $\begin{array}{c}\text { Effet du } \\
\text { gavage }\end{array}$ & Interaction \\
\hline Foie (g) & $\begin{array}{l}\mathrm{G} \\
\mathrm{T}\end{array}$ & $\begin{array}{c}467 \pm 90 a \\
77 \pm 7 c\end{array}$ & $\begin{array}{c}495 \pm 85 a \\
61 \pm 6 c\end{array}$ & $\begin{array}{c}494 \pm 97 a \\
61 \pm 13 c\end{array}$ & $\begin{array}{c}318 \pm 75 b \\
56 \pm 11 c\end{array}$ & $* * *$ & $* * *$ & $* * *$ \\
\hline$A C X$ & $\begin{array}{l}\mathrm{G} \\
\mathrm{T}\end{array}$ & $\begin{array}{l}2,24 \pm 0,90 a \\
0,37 \pm 0,22 b\end{array}$ & $\begin{array}{l}2,07 \pm 1,21 a \\
0,23 \pm 0,13 b\end{array}$ & $\begin{array}{l}1,70 \pm 1,11 a \\
0,34 \pm 0,13 b\end{array}$ & $\begin{array}{l}0,82 \pm 0,42 b \\
0,21 \pm 0,07 b\end{array}$ & * & $* * *$ & * \\
\hline EM & $\begin{array}{l}\mathrm{G} \\
\mathrm{T}\end{array}$ & $\begin{array}{l}5,44 \pm 1,04 \\
1,29 \pm 0,28\end{array}$ & $\begin{array}{l}5,71 \pm 2,01 \\
1,32 \pm 0,25\end{array}$ & $\begin{array}{l}5,21 \pm 1,69 \\
1,37 \pm 0,38\end{array}$ & $\begin{array}{l}5,61 \pm 1,61 \\
1,57 \pm 0,25\end{array}$ & $\mathrm{~ns}$ & $* * *$ & ns \\
\hline G6PDH & $\begin{array}{l}\mathrm{G} \\
\mathrm{T}\end{array}$ & $\begin{array}{l}2,00 \pm 0,54 \\
1,06 \pm 0,22\end{array}$ & $\begin{array}{l}3,15 \pm 0,77 \\
1,68 \pm 0,35\end{array}$ & $\begin{array}{l}3,11 \pm 0,69 \\
1,75 \pm 0,90\end{array}$ & $\begin{array}{l}3,93 \pm 1,19 \\
2,01 \pm 0,44\end{array}$ & $* * *$ & $* * *$ & ns \\
\hline
\end{tabular}

${ }^{*},{ }^{* *},{ }^{* * *}$ : Effet significatif avec $\mathrm{P}<0,05,0,01,0,001-\mathrm{ns}=$ non significatif.

a - $c$ : Différence significative entre lots pour un paramètre donné.

$\mathrm{ACX}=$ acétyl $\mathrm{COA}$ carboxylase, $\mathrm{EM}=$ enzyme malique, $\mathrm{G} 6 \mathrm{PDH}$ = glucose-6-phosphate déshydrogénase. 
Figure 3. Mécanismes de la lipogénèse.
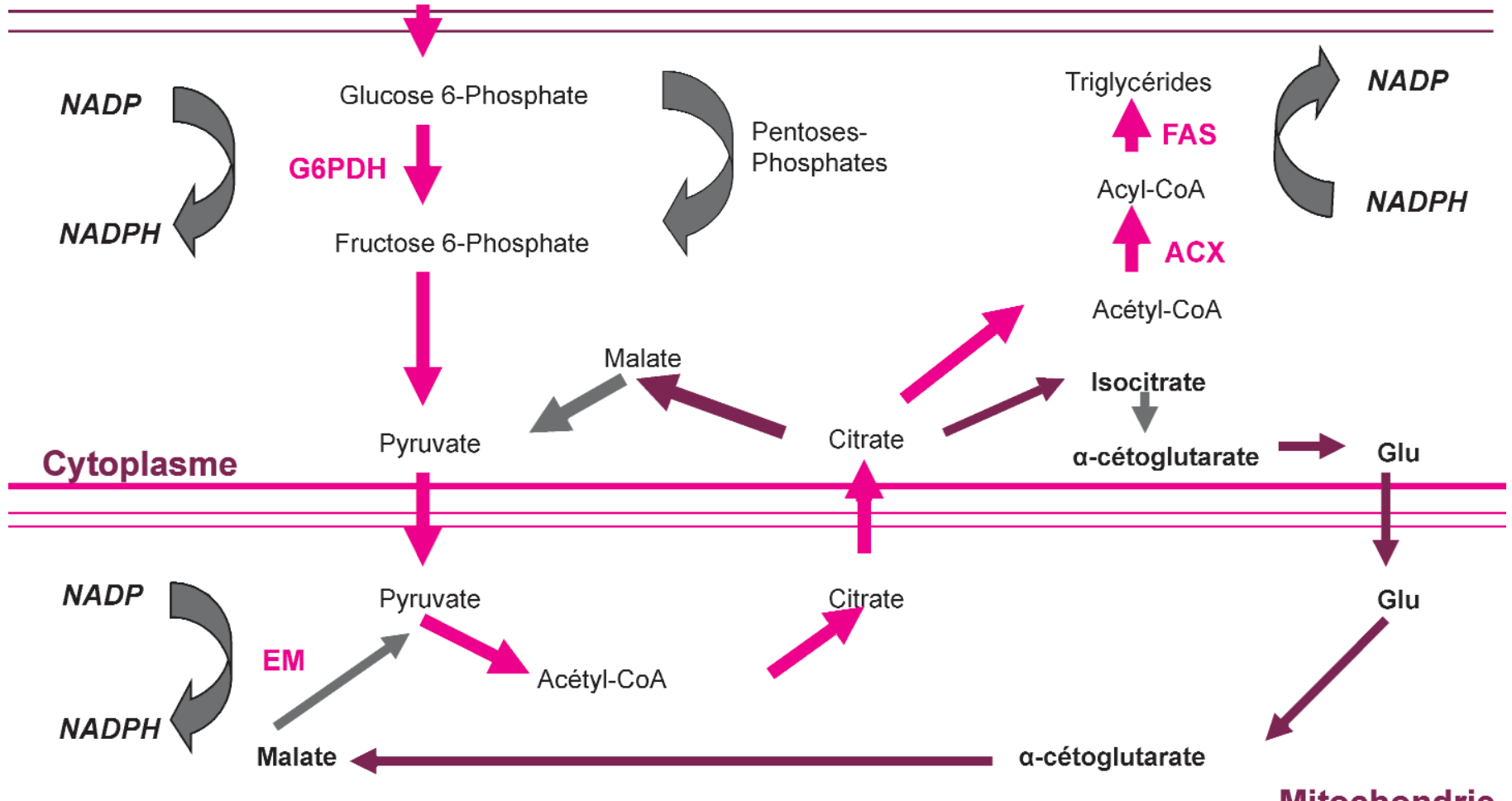

Mitochondrie

G6PDH = Glucose-6-Phosphate Déshydrogénase, EM = enzyme malique.

$\mathrm{NADP}=$ Nicotinamide Adénine Dinucléotide Phosphate, $\mathrm{ACX}=$ acétyl CoA-carboxylase .

L’activité de la FAS est beaucoup plus élevée chez le canard de Barbarie, dont le potentiel de production de foie gras en début de gavage se révèle considérable (tableau 5). Par contre, l'activité de la G6PDH est plus élevée chez le canard Pékin (tableaux 5 et 6) ainsi que celle de EM en particulier en début de gavage. Pour EM et G6PDH, l'augmentation d'activité observée entre animaux maigres et animaux gavés est du même ordre pour tous les génotypes (tableau 6). Par contre, pour ACX cette augmentation est plus élevée chez le canard de Barbarie. Quel que soit le génotype, la synthèse des acides gras ne semble donc pas limitée par la fourniture de NADPH et elle semblerait plus efficace chez le canard de Barbarie. Dans le muscle Pectoralis major, le génotype n'a pas d'effet sur l'activité de ces enzymes. Dans le gras abdominal, l'activité enzymatique de la G6PDH chez les canards Pékin est significativement supérieure à celle des autres génotypes (résultats non présentés). En fin de gavage, chez les oies polonaises, l'activité enzymatique de EM dans le foie est significativement plus faible que chez les oies landaises et ceci malgré une quantité d'aliment ingérée équivalente. La stéatose hépatique serait donc limitée par la fourniture de NADPH pour cette souche car, par ailleurs, les activités enzymatiques de G6PDH, ACX et FAS sont équivalentes (Mourot et al 2000). Par contre, à l'inverse de nos observations réalisées chez le canard de Barbarie, la lipogénèse hépatique serait moins efficace chez les poulets de la lignée maigre (Alleman et al 1999).

\section{2 / Composition chimique du foie et taux de fonte}

Avant gavage, les teneurs en eau et triglycérides du foie des canards Pékin sont supérieures à celles des canards de Barbarie (tableau 7, Hermier et al 2003). Après gavage, la teneur en lipides est supérieure dans le foie des canards de Barbarie, au détriment des teneurs en eau, protéines et minéraux. Les foies des canards de Barbarie ont donc accumulé plus de triglycérides. Une comparaison des foies gras de canards mulards et Barbarie avait montré peu de différence de composition chimique à l'exception du cholestérol libre dont la teneur était plus élevée dans les foies des canards mulards (Salichon et al 1994). La composition en acides gras était également équivalente. Pourtant le génotype a un effet significatif sur le taux de fonte : 22,8, 45,8 et 55,3\% respectivement pour les canards Pékin, mulard et Barbarie dont les poids de foie étaient de 252, 478 et 434 g (Guy et al 1999). Guy et al (1995) avaient déjà observé un taux de fonte supérieur pour les canards de Barbarie comparés aux canards mulards : 55,6 vs 43,9 \% malgré un poids de foie inférieur : 560 vs 702 g. La composition des phospholipides constitutifs des membranes des hépatocytes n'a pas été étudiée chez les différents types de canard et pourrait être impliquée dans les différences de taux de fonte observées chez les canards mulard et Barbarie. Les oies landaises ont des poids de foie gras supérieurs à ceux des oies polonaises (752 vs 570 g, Hermier et al 1999b) et ceci est lié à une augmentation de la teneur en lipides (55 vs $46 \%$ ) essentiellement des triglycérides (52,80 vs 43,29 g/100 g de foie) et des esters de cholestérol $(0,72$ vs 0,39 g/100 g de foie, Hermier et al 
Tableau 7. Effet du génotype sur la composition chimique du foie avant et après gavage (moyenne $\pm E T, n=10$, Hermier et al 2003).

\begin{tabular}{|c|c|c|c|c|c|c|}
\hline \multirow{2}{*}{$\begin{array}{c}\text { Age } \\
\text { Génotypes }\end{array}$} & \multicolumn{3}{|c|}{$\begin{array}{l}\text { Avant gavage } \\
11,5 \text { semaines }\end{array}$} & \multicolumn{3}{|c|}{$\begin{array}{l}\text { Après gavage } \\
13 \text { semaines }\end{array}$} \\
\hline & Barbarie & Pékin & $\begin{array}{l}\text { Effet du } \\
\text { génotype }\end{array}$ & Barbarie & Pékin & $\begin{array}{c}\text { Effet du } \\
\text { génotype }\end{array}$ \\
\hline Eau $(\%)$ & $71,5 \pm 0,9$ & $72,7 \pm 1,7$ & * & $32,0 \pm 3,4$ & $39,6 \pm 4,8$ & $* * *$ \\
\hline Protéines (\%) & $22,7 \pm 0,9$ & $22,5 \pm 0,9$ & ns & $7,29 \pm 1,5$ & $9,65 \pm 1,8$ & $* * *$ \\
\hline Minéraux (\%) & $1,5 \pm 0,1$ & $1,5 \pm 0,2$ & ns & $0,9 \pm 0,2$ & $1,2 \pm 0,2$ & * \\
\hline Lipides (\%) & $4,8 \pm 1,1$ & $4,8 \pm 0,6$ & ns & $61,9 \pm 7,4$ & $50,1 \pm 6,6$ & *** \\
\hline Triglycérides (\% lipides) & $5,9 \pm 2,7$ & $10,4 \pm 2,9$ & ** & $96,7 \pm 0,9$ & $93,7 \pm 1,7$ & $* * *$ \\
\hline Esters de cholestérol (\% lipides) & $18,7 \pm 9,6$ & $22,3 \pm 9,7$ & ns & $0,3 \pm 0,3$ & $0,9 \pm 0,5$ & $* \star$ \\
\hline Cholestérol libre (\% lipides) & $7,8 \pm 1,4$ & $7,0 \pm 0,6$ & ns & $0,2 \pm 0,1$ & $0,5 \pm 0,1$ & $* * *$ \\
\hline Phospholipides (\% lipides) & $67,6 \pm 8,7$ & $60,3 \pm 10,8$ & ns & $2,7 \pm 0,7$ & $4,9 \pm 1,7$ & $* * *$ \\
\hline
\end{tabular}

${ }^{*},{ }^{* *},{ }^{* * *}$ : Effet significatif avec $\mathrm{P}<0,05,0,01,0,001-\mathrm{ns}=$ non significatif.

1999b). Par contre les teneurs en phospholipides et cholestérol libre sont supérieures dans les foies des oies polonaises $(1,93$ vs $1,30 \mathrm{~g} / 100 \mathrm{~g}$ de foie et 0,12 vs $0,05 \mathrm{~g} / 100 \mathrm{~g}$ de foie respectivement). Le profil des acides gras du foie gras est très voisin dans les deux races (Hermier et al 1999a).

\section{5 / Circulation sanguine des nutriments énergétiques}

\section{1 / Lipides circulants}

Après un jeûne de plus de $12 \mathrm{~h}$, les canards de Barbarie maigres, âgés de 14 semaines, présentent les concentrations plasmatiques en phospholipides et en cholestérol total les plus faibles par comparaison avec les autres génotypes (tableau 8). Après gavage, ce sont les canards Pékin et hinnies qui présentent les teneurs en phospholipides, triglycérides et cholestérol total les plus importantes. En comparant des canards Pékin et Barbarie à jeun depuis 18 h, avant la préparation au gavage à l'âge de 11,5 semaines et à la fin du gavage à l'âge de 15 semaines, Hermier et al
(2003) avaient également observé des concentrations plasmatiques des différents lipides et lipoprotéines significativement supérieures chez les canards Pékin ce qui suggère pour ce génotype une capacité d'exportation des lipides plus importante. Chez les oiseaux, cette dernière est en principe associée à un développement plus important des tissus adipeux périphériques (Hermier 1997). Avant prégavage, la composition des VLDL était similaire dans les deux génotypes à l'exception d'une proportion d'esters du cholestérol plus importante chez le canard Pékin et en fin de gavage les proportions de cholestérol libre et de phospholipides était plus importantes chez le canard Pékin, celle des triglycérides était inférieure (Hermier et al 2000). L'analyse de la concentration en triacylglycérol des portomicrons et des VLDL avant le premier repas de gavage et $2 \mathrm{~h}$ après a permis de confirmer que cette concentration était plus faible chez les canards Pékin (Davail et al 2003). Par contre, l'augmentation de la concentration en triacylglycérol des portomicrons et des VLDL consécutive au repas était plus conséquente pour les canards Pékin.
Guy et al (1999) avaient également analysé la concentration plasmatique des lipides juste avant le $2^{\mathrm{e}}$ repas de gavage, puis 60, 180 et 360 mn après. La concentration en triglycérides et phospholipides plasmatiques était plus importante chez les canards mulards et Pékin par comparaison avec le canard de Barbarie. Entre T0 et T360 mn, la concentration en triglycérides plasmatiques était multipliée par 2,6, 1,4 et 1,7 respectivement chez les canards Pékin, mulards et Barbarie présentant des concentrations initiales de 2,29, 2,64 et $1,26 \mathrm{~g} / \mathrm{l}$. En fin de gavage, les oies polonaises ont des teneurs plasmatiques pour les différentes lipoprotéines, les triglycérides, les phospholipides et le cholestérol libre plus élevées que les oies landaises (Fournier et al 1997). De l'analyse de la composition en lipides et en acides gras des différentes lipoprotéines, il ressort que l'oie landaise présente un défaut d'incorporation des triglycérides dans les VLDL (Hermier et al 1991, Fournier et al 1997) et un défaut d'incorporation de la phosphatidyl choline et des acides gras polyinsaturés dans les HDL (High Density Lipoprotein) ce qui va favori-

Tableau 8. Effet du génotype et du gavage sur les lipides circulants (mmol/l), la glycémie ( $\mathrm{g} / \mathrm{l})$ et l'insulinémie ( $\mu U / \mathrm{ml})$ chez des canards âgés de 14 semaines, sacrifiés plus de $12 \mathrm{~h}$ après leur dernier repas ( $G$ = gavés, $T=$ témoins, moyenne $\pm E T, n=8$ ).

\begin{tabular}{|c|c|c|c|c|c|c|}
\hline Paramètres sa & & Phospholipides & Triglycérides & Cholestérol total & Glycémie & Insulinémie \\
\hline Barbarie & $\begin{array}{l}G \\
T\end{array}$ & $\begin{array}{l}4,98 \pm 1,02 b \\
2,76 \pm 0,54 c\end{array}$ & $\begin{array}{l}2,42 \pm 0,82 b \\
0,85 \pm 0,27 c\end{array}$ & $\begin{array}{c}5,86 \pm 0,92 b c \\
3,85 \pm 0,63 c\end{array}$ & $\begin{array}{l}1,87 \pm 0,24 \\
1,78 \pm 0,70\end{array}$ & $\begin{array}{c}12,7 \pm 2,0 \\
8,8 \pm 1,3\end{array}$ \\
\hline Hinny & $\begin{array}{l}\mathrm{G} \\
\mathrm{T}\end{array}$ & $\begin{array}{c}7,10 \pm 1,83 a \\
3,98 \pm 0,61 b c\end{array}$ & $\begin{array}{l}3,37 \pm 1,41 a \\
0,89 \pm 0,19 c\end{array}$ & $\begin{array}{c}8,60 \pm 3,11 \mathrm{a} \\
4,67 \pm 0,77 \mathrm{bc}\end{array}$ & $\begin{array}{l}1,90 \pm 0,12 \\
1,70 \pm 0,14\end{array}$ & $\begin{array}{c}13,8 \pm 1,3 \\
6,2 \pm 0,9\end{array}$ \\
\hline Mulard & $\begin{array}{l}G \\
T\end{array}$ & $\begin{array}{c}5,15 \pm 1,15 b \\
4,12 \pm 0,41 b c\end{array}$ & $\begin{array}{c}2,98 \pm 0,89 a b \\
0,93 \pm 0,39 c\end{array}$ & $\begin{array}{c}6,23 \pm 1,51 b \\
5,18 \pm 0,66 b c\end{array}$ & $\begin{array}{l}1,82 \pm 0,15 \\
1,63 \pm 0,11\end{array}$ & $\begin{array}{c}14,4 \pm 2,0 \\
6,5 \pm 0,8\end{array}$ \\
\hline Pékin & $\begin{array}{l}\mathrm{G} \\
\mathrm{T}\end{array}$ & $\begin{array}{c}7,09 \pm 1,55 a \\
3,96 \pm 0,74 \mathrm{bc}\end{array}$ & $\begin{array}{l}3,88 \pm 1,00 a \\
0,78 \pm 0,19 c\end{array}$ & $\begin{array}{c}8,81 \pm 2,03 a \\
4,71 \pm 0,94 b c\end{array}$ & $\begin{array}{l}1,62 \pm 0,14 \\
1,56 \pm 0,14\end{array}$ & $\begin{array}{c}10,9 \pm 2,4 \\
6,0 \pm 1,1\end{array}$ \\
\hline $\begin{array}{l}\text { Effet génotype } \\
\text { Effet gavage } \\
\text { Interaction }\end{array}$ & & $\begin{array}{c}* \star \star \\
* * \star \\
*\end{array}$ & $\begin{array}{c}\mathrm{ns} \\
* * * \\
*\end{array}$ & $\begin{array}{c}* * \\
* * * \\
*\end{array}$ & $\begin{array}{l}* * * \\
* * * \\
\mathrm{~ns}\end{array}$ & $\begin{array}{l}\mathrm{nS} \\
* * * \\
\mathrm{~ns}\end{array}$ \\
\hline
\end{tabular}

${ }^{*},{ }^{* *},{ }^{* * *}$ : Effet significatif à $\mathrm{P}<0,05, \mathrm{P}<0,01$ ou $\mathrm{P}<0,001-\mathrm{ns}=$ non significatif.

a - $C$ : Différence significative entre lots pour un critère donné 
ser la croissance des membranes des hépatocytes et faciliter leur hypertrophie (Hermier et al 1999b). Chez les poulets maigres, la concentration en lipides et lipoprotéines plasmatiques est inférieure à celle des poulets gras (Alleman et al 1999). Toutefois, les VLDL des deux génotypes ne se distinguent pas par leur composition. D'une façon générale, les oiseaux présentant un engraissement périphérique important présentent donc toujours des taux circulants de lipides et lipoprotéines plus élevés que les génotypes maigres. Les mécanismes de régulation de la synthèse et de la sécrétion des VLDL chez les canards gavés méritent toutefois d'être approfondis.

\section{2 / Glycémie}

La glycémie la plus faible est observée chez les canards Pékin (Hermier et al 2003, tableau 8). Constans et al (1991) avaient déjà mis en évidence cette différence de glycémie entre canards de Barbarie et Pékin. Ils l'attribuaient en partie à un nombre inférieur de récepteurs à insuline sur les membranes des hépatocytes des canards de Barbarie. En mesurant la glycémie 90 $\mathrm{mn}$ après un repas, au $10^{\mathrm{e}}$ jour du gavage, Davail et al (2003) ont confirmé que sa valeur était plus élevée chez les canards de Barbarie par comparaison avec les canards mulards et Pékin : 2,97 vs 1,99 et $1,94 \mathrm{~g} / \mathrm{l}$. Cependant en cinétique post-prandiale sur le premier repas de gavage, une hyperglycémie transitoire est observée chez les canards Pékin et Barbarie uniquement. Chez les canards mulards elle n'est pas mise en évidence. Davail et al (2003) suggèrent que cette différence pourrait être expliquée par une lipogénèse hépatique à partir du glucose plus efficace chez le canard mulard. Toutefois, il faut rappeler que dans cette étude, les quantités d'aliment distribuées étaient ajustées aux poids vifs des génotypes et non pas à leur capacité d'ingestion. En fin de gavage, les oies landaises ont également une glycémie beaucoup plus élevée que les oies polonaises (3,16 vs 1,86 g/l, Fournier et al 1997) alors qu'au début du gavage la glycémie est équivalente chez les deux races. Les poulets maigres se caractérisent également par une glycémie à jeun et à l'état nourri plus élevée que celle des gras. Alleman et al (1999) suggéraient une utilisation métabolique moins intense du glucose chez ces poulets confirmée par les tests de tolérance au glucose et les tests de sensibilité à l'insuline.

\section{6 / Rôle de l'insuline}

La glycémie est régulée en partie par l'insuline. Après le premier repas de gavage, les canards Pékin, mulards et Barbarie ont des concentrations plasmatiques d'insuline et de glucagon similaires, mais le ratio insuline/glucagon est significativement plus faible chez les canards Pékin. Ceci suggère une lipogénèse moins intense pour ce génotype (Davail et al 2003). Par contre, en mesurant la concentration plasmatique en insuline, $90 \mathrm{mn}$ après un repas au 10 $10^{\mathrm{e}}$ jour du gavage, Davail et al (2003) ont montré que sa valeur était bien supérieure chez les canards Pékin par comparaison avec les canards mulards et Barbarie : 77,5 vs 37,8 et $32,4 \mu \mathrm{U} / \mathrm{ml}$ ce qui pourrait favoriser la captation du glucose par le foie et la synthèse hépatique de triglycérides ainsi que la dégradation des triglycérides circulants par la lipoprotéine lipase

Tableau 9. Effets du gavage et du génotype sur la teneur en lipides totaux (\%) du Pectoralis major (muscle du bréchet), de l'lliotibialis superficialis (muscle de la cuisse), du gras abdominal et du gras inter-musculaire de la cuisse ( $G$ = gavés, $T$ = témoins, moyenne $\pm E T, n=8$ ).

\begin{tabular}{|lc|c|c|c|c|}
\hline \multicolumn{2}{|c|}{ Tissus } & $\begin{array}{c}\text { Pectoralis } \\
\text { major }\end{array}$ & $\begin{array}{c}\text { Ilotibialis } \\
\text { superficialis }\end{array}$ & $\begin{array}{c}\text { Gras } \\
\text { abdominal }\end{array}$ & $\begin{array}{c}\text { Gras inter- } \\
\text { musculaire }\end{array}$ \\
\hline Barbarie & G & $3,65 \pm 0,51$ & $2,52 \pm 0,61$ & $94,60 \pm 3,22$ & $69,29 \pm 16,60$ \\
& T & $2,26 \pm 0,36$ & $2,16 \pm 0,29$ & $89,00 \pm 9,14$ & nd \\
\hline Hinny & G & $5,92 \pm 0,98$ & $3,99 \pm 0,97$ & $93,23 \pm 4,02$ & $69,58 \pm 19,10$ \\
& T & $3,87 \pm 1,44$ & $3,16 \pm 0,61$ & $91,89 \pm 4,55$ & nd \\
\hline Mulard & G & $5,24 \pm 0,96$ & $3,74 \pm 0,61$ & $90,98 \pm 10,61$ & $75,04 \pm 14,49$ \\
& T & $3,13 \pm 0,54$ & $2,79 \pm 0,39$ & $89,39 \pm 5,84$ & nd \\
\hline Pékin & G & $7,57 \pm 0,85$ & $5,73 \pm 0,76$ & $96,88 \pm 3,23$ & $80,42 \pm 19,53$ \\
& $\mathrm{~T}$ & $4,59 \pm 0,68$ & $4,55 \pm 0,54$ & $91,35 \pm 4,12$ & $\mathrm{nd}$ \\
\hline Effet génotype & $* * *$ & $* * *$ & $\mathrm{~ns}$ & $\mathrm{~ns}$ \\
Effet gavage & $* * *$ & $* * *$ & $*$ & $\mathrm{nd}$ \\
Interaction & $\mathrm{ns}$ & $\mathrm{ns}$ & $\mathrm{ns}$ & $\mathrm{ns}$ \\
\hline
\end{tabular}

${ }^{*},{ }^{* *},{ }^{* * *}$ : Effet significatif à $\mathrm{P}<0,05, \mathrm{P}<0,01$ ou $\mathrm{P}<0,001-\mathrm{ns}=$ non significatif - nd $=$ non déterminé. et par conséquent la captation des acides gras par les tissus périphériques. Chez des canards des quatre génotypes, âgés de 14 semaines et à jeun depuis plus de $12 \mathrm{~h}$, l’insulinémie est équivalente (tableau 8). Le rôle de l'insuline n’a jamais été évalué chez les oies landaises et polonaises gavées.

\section{7 / Dépôts périphériques des lipides}

L’activité de la lipoprotéine lipase mesurée $90 \mathrm{mn}$ après le premier repas de gavage est équivalente chez les canards Pékin, Barbarie et mulards : 3,2 à $4,5 \mu \mathrm{mol}$ de palmitate $/ \mathrm{h} / \mathrm{ml}$ (Davail et al 2003). Après 10 jours de gavage, cette activité chute fortement chez les canards de Barbarie et mulards (respectivement à 14 et $28 \%$ de la valeur initiale) et reste élevée chez les canards Pékin (79 \% de la valeur initiale) liée à une insulinémie plus élevée. La capacité d’hydrolyse des triglycérides circulants demeure donc plus importante chez les canards Pékin ce qui va se traduire par des dépôts plus importants de lipides dans les tissus périphériques musculaires et adipeux (tableau 9). L’activité de la LPL a été mesurée chez les oies landaises et polonaises âgées de 10 semaines et $1 \mathrm{~h}$ après un repas par Davail et al (2000). Cette activité était similaire pour les deux races d'oies. Toutefois, la corrélation entre l'activité LPL mesurée à 10 semaines chez les oies landaises et leur poids de foie gras mesuré à l'âge de 25 semaines était de -0,42. L'activité de la LPL du tissu adipeux abdominal est plus faible chez les poulets maigres par comparaison avec les poulets gras (Alleman et al 1999). Les mécanismes de régulation de l'activité de la LPL dans des situations de lipogénèse intense méritent d'être approfondis.

Le canard de Barbarie présente les teneurs les plus faibles en lipides totaux, triglycérides et acides gras mono-insaturés (AGMI) dans les tissus périphériques musculaires et adipeux (tableaux 9 et 10, Chartrin et al 2003). Les oiseaux synthétisent surtout des AGMI (acides oléique et palmitoléique, Klasing 1998). Le canard Pékin va donc accumuler plus de triglycérides d'origine hépatique et donc d'AGMI dans ses tissus périphériques au détriment des acides gras saturés et polyinsaturés (AGPI) d’origine alimentaire. De plus, le développement corporel du canard Pékin est plus précoce que celui des autres génotypes, en particulier 
Tableau 10. Effet du génotype et du gavage sur les classes de lipides et la composition en acides gras de l'lliotibialis superficialis de canards âgés de 14 semaines ( $G$ = gavés, $T$ = témoins, moyenne $\pm E T, n=8$ ).

\begin{tabular}{|c|c|c|c|c|c|c|c|c|}
\hline \multicolumn{2}{|c|}{ Génotypes } & Barbarie & Hinny & Mulard & Pékín & $\begin{array}{l}\text { Effet du } \\
\text { génotype }\end{array}$ & $\begin{array}{l}\text { Effet du } \\
\text { gavage }\end{array}$ & Interaction \\
\hline $\begin{array}{l}\text { Triglycérides } \\
(\mathrm{g} / 100 \mathrm{~g})\end{array}$ & $\begin{array}{l}G \\
T\end{array}$ & $\begin{array}{l}1,54 \pm 0,48 \\
1,30 \pm 0,32\end{array}$ & $\begin{array}{l}2,75 \pm 0,82 \\
2,12 \pm 0,56\end{array}$ & $\begin{array}{l}2,55 \pm 0,56 \\
1,88 \pm 0,30\end{array}$ & $\begin{array}{l}4,20 \pm 0,68 \\
3,39 \pm 0,51\end{array}$ & $* * *$ & $\star * * *$ & ns \\
\hline $\begin{array}{l}\text { Cholestérol } \\
\text { (g/100 g) }\end{array}$ & $\begin{array}{l}G \\
T\end{array}$ & $\begin{array}{l}0,11 \pm 0,02 \\
0,12 \pm 0,02\end{array}$ & $\begin{array}{l}0,14 \pm 0,03 \\
0,13 \pm 0,03\end{array}$ & $\begin{array}{l}0,14 \pm 0,01 \\
0,11 \pm 0,01\end{array}$ & $\begin{array}{l}0,17 \pm 0,04 \\
0,15 \pm 0,04\end{array}$ & $\star * *$ & ns & ns \\
\hline $\begin{array}{l}\text { Phospholipides } \\
\text { (g/100 g) }\end{array}$ & $\begin{array}{l}\mathrm{G} \\
\mathrm{T}\end{array}$ & $\begin{array}{l}0,87 \pm 0,19 \\
0,73 \pm 0,08\end{array}$ & $\begin{array}{l}1,10 \pm 0,16 \\
0,90 \pm 0,07\end{array}$ & $\begin{array}{l}1,05 \pm 0,12 \\
0,80 \pm 0,11\end{array}$ & $\begin{array}{l}1,35 \pm 0,18 \\
1,00 \pm 0,07\end{array}$ & $* *$ & $* * *$ & ns \\
\hline AGS (\%) & $\begin{array}{l}G \\
T\end{array}$ & $\begin{array}{l}36,19 \pm 1,19 \\
36,44 \pm 2,85\end{array}$ & $\begin{array}{l}35,61 \pm 1,39 \\
33,49 \pm 1,82\end{array}$ & $\begin{array}{l}34,46 \pm 1,16 \\
32,82 \pm 0,46\end{array}$ & $\begin{array}{l}31,43 \pm 1,53 \\
28,77 \pm 1,28\end{array}$ & $\star * *$ & $* * *$ & ns \\
\hline AGMI (\%) & $\begin{array}{l}G \\
T\end{array}$ & $\begin{array}{l}47,45 \pm 1,51 \\
45,46 \pm 2,17\end{array}$ & $\begin{array}{l}49,66 \pm 1,63 \\
47,71 \pm 1,22\end{array}$ & $\begin{array}{l}50,31 \pm 0,94 \\
48,43 \pm 2,22\end{array}$ & $\begin{array}{l}55,00 \pm 1,49 \\
54,73 \pm 1,96\end{array}$ & $* * *$ & $* * *$ & ns \\
\hline AGPI (\%) & $\begin{array}{l}G \\
T\end{array}$ & $\begin{array}{l}16,36 \pm 1,50 \\
18,11 \pm 3,71\end{array}$ & $\begin{array}{l}14,72 \pm 0,84 \\
18,80 \pm 0,96\end{array}$ & $\begin{array}{l}15,23 \pm 1,36 \\
18,75 \pm 1,92\end{array}$ & $\begin{array}{l}13,57 \pm 0,53 \\
16,50 \pm 1,33\end{array}$ & $* *$ & $* * *$ & ns \\
\hline
\end{tabular}

${ }^{*},{ }^{* *},{ }^{* * *}$ : Effet significatif avec $\mathrm{P}<0,05,0,01,0,001-\mathrm{ns}=$ non significatif.

AGS, AGMI, AGPI = Acides Gras Saturés, Mono-Insaturés, Poly-Insaturés.

celui du canard de Barbarie. Les tissus adipeux vont donc se former plus tôt chez le canard Pékin. Guy et al (1995), Larzul et al (2002) et Hermier et al (2003) avaient également mis en évidence une teneur en lipides totaux inférieure dans le filet des canards de Barbarie par comparaison avec les autres génotypes, la différence s’accentuant chez les animaux gavés. Par contre, la teneur en lipides des muscles est équivalente chez les oies landaises et polonaises (Davail et al 2000) et chez les poulets maigres et gras (Alleman et al 1999).

Au sein des muscles, les lipides vont s'accumuler majoritairement dans des adipocytes dont la surface relative sur des coupes transversales de muscles est plus importante chez les canards Pékin maigres et gavés (tableau 11, Chartrin et al 2004). Les lipides sont aussi stockés dans les fibres musculaires dont la teneur en triglycérides est supérieure également dans le Pectoralis major des canards Pékin (Chartrin et al 2004). Cet afflux de lipides dans les muscles va modifier l'orientation de leur métabolisme énergétique. En effet, dans le $P$. major, les canards de Barbarie présentent une activité pour la $\beta$-hydroxyacyl déshydrogénase (HAD), marqueur du métabolisme oxydatif, inférieure à celle des autres génotypes (tableau 12). A l'exception du canard de Barbarie, l'activité de la lactate déshydrogénase (LDH), marqueur du métabolisme glycolytique, est inférieure chez les

Tableau 11. Effet du génotype et du gavage sur la surface relative occupée par les adipocytes sur une coupe transversale du Pectoralis major (muscle du bréchet) et du Sartorius (muscle de la cuisse) de canards âgés de 14 semaines ( $G=$ gavés, $T=$ témoins, moyenne $\pm E T, n=8)$.

\begin{tabular}{|c|c|c|c|c|c|c|c|c|}
\hline \multicolumn{2}{|c|}{ Génotypes } & Barbarie & Hinny & Mulard & Pékin & $\begin{array}{l}\text { Effet du } \\
\text { génotype }\end{array}$ & $\begin{array}{l}\text { Effet du } \\
\text { gavage }\end{array}$ & Interaction \\
\hline P. major & $\begin{array}{l}G \\
T\end{array}$ & $\begin{array}{l}1,98 \pm 0,39 c \\
1,15 \pm 0,34 d\end{array}$ & $\begin{array}{l}3,74 \pm 0,95 b \\
2,47 \pm 0,34 c\end{array}$ & $\begin{array}{l}3,52 \pm 0,94 b \\
2,60 \pm 0,66 c\end{array}$ & $\begin{array}{l}5,73 \pm 0,85 a \\
3,59 \pm 0,62 b\end{array}$ & $* * * *$ & $* * *$ & $*$ \\
\hline Sartorius & $\begin{array}{l}G \\
T\end{array}$ & $\begin{array}{l}2,40 \pm 0,53 \mathrm{c} \\
1,07 \pm 0,39 \mathrm{~d}\end{array}$ & $\begin{array}{c}3,63 \pm 0,68 \mathrm{~b} \\
1,88 \pm 0,45 \mathrm{~cd}\end{array}$ & $\begin{array}{c}3,58 \pm 1,15 b \\
2,00 \pm 0,46 \mathrm{~cd}\end{array}$ & $\begin{array}{l}5,27 \pm 1,77 \mathrm{a} \\
2,26 \pm 0,60 \mathrm{c}\end{array}$ & $* * *$ & $* * *$ & * \\
\hline
\end{tabular}

$*{ }^{* *}, * * *$ : Effet significatif avec $\mathrm{P}<0,05,0,01,0,001-$ ns $=$ non significatif.

a' - d' : Différence significative entre lots pour un paramètre donné.

Tableau 12. Effets du gavage et du génotype sur l'activité enzymatique (UI/g) de la lactate déshydrogénase (LDH) et de la $\beta$-hydroxyacyl déshydrogénase (HAD) dans le Pectoralis major (PM, muscle du bréchet) et le Sartorius (ST, muscle de la cuisse) de canards âgés de 14 semaines ( $G$ = gavés, $T=$ témoins, moyenne $\pm E T, n=8)$.

\begin{tabular}{|c|c|c|c|c|c|}
\hline \multicolumn{2}{|c|}{ Enzymes } & LDH PM & HAD PM & LDH ST & HAD ST \\
\hline Barbarie & $\begin{array}{l}G \\
T\end{array}$ & $\begin{array}{c}506,10 \pm 90,73 a \\
488,55 \pm 55,85 a b\end{array}$ & $\begin{array}{c}13,70 \pm 3,15 \\
9,58 \pm 3,09\end{array}$ & $\begin{array}{l}382,25 \pm 53,64 \\
403,17 \pm 85,02\end{array}$ & $\begin{array}{l}5,76 \pm 1,53 \\
4,52 \pm 1,06\end{array}$ \\
\hline Hinny & $\begin{array}{l}G \\
T\end{array}$ & $\begin{array}{c}396,59 \pm 36,17 \mathrm{c} \\
497,48 \pm 47,07 \mathrm{ab}\end{array}$ & $\begin{array}{l}17,20 \pm 1,80 \\
16,39 \pm 2,51\end{array}$ & $\begin{array}{l}449,48 \pm 44,49 \\
399,79 \pm 66,75\end{array}$ & $\begin{array}{l}6,51 \pm 1,75 \\
6,54 \pm 1,46\end{array}$ \\
\hline Mulard & $\begin{array}{l}G \\
T\end{array}$ & $\begin{array}{l}440,85 \pm 67,60 a b c \\
455,66 \pm 81,52 a b c\end{array}$ & $\begin{array}{l}17,64 \pm 2,39 \\
15,84 \pm 2,73\end{array}$ & $\begin{array}{l}431,19 \pm 81,26 \\
443,26 \pm 96,80\end{array}$ & $\begin{array}{l}5,85 \pm 1,57 \\
4,96 \pm 1,37\end{array}$ \\
\hline Pékín & $\begin{array}{l}G \\
T\end{array}$ & $\begin{array}{l}409,61 \pm 60,21 b c \\
494,92 \pm 38,00 a b\end{array}$ & $\begin{array}{l}17,77 \pm 4,27 \\
16,86 \pm 2,97\end{array}$ & $\begin{array}{l}438,36 \pm 56,07 \\
447,35 \pm 45,18\end{array}$ & $\begin{array}{l}5,64 \pm 1,35 \\
5,48 \pm 1,30\end{array}$ \\
\hline $\begin{array}{l}\text { Effet géno } \\
\text { Effet gava } \\
\text { Interaction }\end{array}$ & & $\begin{array}{l}\mathrm{ns} \\
\star * \\
*\end{array}$ & $\begin{array}{c}* * * \\
* \\
\mathrm{~ns}\end{array}$ & $\begin{array}{l}\text { ns } \\
\text { ns } \\
\text { ns }\end{array}$ & $\begin{array}{l}* \\
\text { ns } \\
\text { ns }\end{array}$ \\
\hline
\end{tabular}

${ }^{*},{ }^{* *},{ }^{* * *}:$ Effet significatif à $\mathrm{P}<0,05, \mathrm{P}<0,01$ ou $\mathrm{P}<0,001-\mathrm{ns}=$ non significatif.

a - c : Différence significative entre lots pour un paramètre donné 
canards gavés par comparaison avec les canards maigres (tableau 12). Dans le Sartorius, les canards de Barbarie présentent aussi l'activité HAD la plus faible. Par contre, dans ce muscle, le génotype et le gavage n'ont pas d'effet sur l'activité de la LDH. L'enrichissement en lipides du muscle est accompagné par une capacité supérieure d'oxydation des acides gras pour satisfaire ses besoins énergétiques et, selon les muscles, par une moindre utilisation du glucose.

\section{8 / Qualité sensorielle de la viande}

Par comparaison avec les autres génotypes, les filets de canard de Barbarie sont les plus clairs, les moins rouges et les plus jaunes (tableau 13). Les filets de canard Pékin sont les plus foncés et les moins jaunes. Ce sont les filets des canards hinny et mulard qui présentent les intensités de rouge les plus élevées. Chez les canards de Barbarie, le fort développement musculaire pourrait avoir entraîné une dilution des pigments héminiques (myoglobine, hémoglobine). Ce phénomène a déjà été démontré chez le poulet par Berri et al (2001). Par ailleurs, le canard de Barbarie a un développement moins précoce que les autres génotypes. Or, la teneur en pigments héminiques du muscle augmente avec l'âge (Baéza et al 2002). La teneur en pigments héminiques dans le filet de canard de Barbarie pourrait ne pas avoir atteint son niveau maximal contrairement aux autres génotypes.

Les filets de canard Pékin perdent plus de jus à la cuisson que ceux des
Tableau 13. Effet du génotype et du gavage sur la couleur et les pertes à la cuisson des filets de canards âgés de 14 semaines ( $G=$ gavés, $T=$ témoins, moyenne $\pm E T$ ).

\begin{tabular}{|c|c|c|c|c|c|c|}
\hline \multirow{2}{*}{\multicolumn{2}{|c|}{ Paramètres }} & \multirow{2}{*}{$\mathrm{n}$} & \multicolumn{3}{|c|}{ Couleur du filet } & \multirow{2}{*}{$\begin{array}{l}\text { Pertes à la } \\
\text { cuisson }(\%)\end{array}$} \\
\hline & & & $L^{*}$ & $\mathbf{a}^{*}$ & $b^{*}$ & \\
\hline \multirow[t]{2}{*}{ Pékin } & $G$ & 11 & $41,51 \pm 4,30$ & $13,79 \pm 0,99$ & $13,63 \pm 2,02 b$ & $21,08 \pm 2,18 a$ \\
\hline & $\mathrm{T}$ & 20 & $30,85 \pm 1,35$ & $13,66 \pm 1,28$ & $8,20 \pm 1,31 \mathrm{~d}$ & $16,90 \pm 2,18 b$ \\
\hline \multirow[t]{2}{*}{ Mulard } & $G$ & 21 & $41,18 \pm 3,65$ & $14,21 \pm 1,16$ & $14,33 \pm 2,02 a b$ & $15,86 \pm 1,52 b$ \\
\hline & $\mathrm{T}$ & 20 & $31,90 \pm 1,81$ & $13,78 \pm 0,97$ & $8,93 \pm 1,39 d$ & $14,51 \pm 1,60 \mathrm{c}$ \\
\hline \multirow[t]{2}{*}{ Hinny } & $\mathrm{G}$ & 21 & $42,89 \pm 1,58$ & $14,06 \pm 1,55$ & $15,03 \pm 1,93 a$ & $16,61 \pm 2,31 b$ \\
\hline & $T$ & 20 & $32,15 \pm 1,93$ & $13,88 \pm 1,69$ & $9,24 \pm 2,16 \mathrm{~d}$ & $14,70 \pm 1,56 \mathrm{c}$ \\
\hline \multirow[t]{2}{*}{ Barbarie } & $G$ & 15 & $43,63 \pm 3,07$ & $12,80 \pm 0,92$ & $14,73 \pm 2,02 \mathrm{ab}$ & $16,98 \pm 1,92 b$ \\
\hline & $T$ & 17 & $34,97 \pm 2,05$ & $13,63 \pm 0,89$ & $11,43 \pm 1,11 \mathrm{c}$ & $14,63 \pm 1,45 c$ \\
\hline \multicolumn{3}{|c|}{ Effet génotype } & $* * *$ & * & $* * *$ & $* \star *$ \\
\hline \multicolumn{3}{|c|}{ Effet gavage } & *** & ns & $* * *$ & **** \\
\hline \multicolumn{3}{|c|}{ Interaction } & ns & ns & * & * \\
\hline
\end{tabular}

${ }^{*}, * * * * *$ : Effet significatif à $P<0,05, P<0,01$ ou $P<0,001-n s=$ non significatif,

a - $d$ : Différence significative entre lots pour un paramètre donné.

$\mathrm{L}^{\star}=$ luminance $(0=$ noir et $100=$ blanc $), \mathrm{a}^{\star}=$ intensité de rouge, $\mathrm{b}^{*}=$ intensité de jaune autres génotypes probablement en liaison avec leur teneur en lipides plus élevée (tableau 13). Toutefois cela n’affecte pas leur jutosité. Ils sont également jugés plus tendres et moins fibreux que ceux des autres génotypes (tableau 14) et la force de conpression-cisaillement est inférieure à celle des filets des autres génotypes (tableau 15). A l'opposé, les filets des canards de Barbarie ont les notes les plus faibles pour la ten- dreté, la jutosité et la flaveur et la note la plus élevée pour la fibrosité. Ce sont les filets des canards hinny qui présentent la note de flaveur la plus élevée. Larzul et al (2002) avaient montré également que les magrets des canards de Barbarie présentaient une force de résistance à la compression et au cisaillement supérieure à celle des autres génotypes. Cette dureté accrue pourrait être induite par la teneur en
Tableau 15. Effet du génotype sur la force maximale de cisaillement de la viande cuite, la teneur en collagène total et la solubilité du collagène dans le magret de canards gavés, âgés de 15 semaines (moyenne, $n=25$, Larzul et al 2002).

\begin{tabular}{|l|c|c|c|c|}
\hline \multicolumn{1}{|c|}{ Génotypes } & Barbarie & Hinny & Mulard & Pékin \\
\hline Force de cisaillement (N) & $62,6 \mathrm{a}$ & $46,0 \mathrm{ab}$ & $46,6 \mathrm{ab}$ & $33,2 \mathrm{~b}$ \\
Collagène total $(\mathrm{mg} / \mathrm{g})$ & $4,82 \mathrm{a}$ & $4,38 \mathrm{ab}$ & $4,45 \mathrm{a}$ & $4,30 \mathrm{~b}$ \\
Collagène soluble $(\%)$ & $12,99 \mathrm{~b}$ & $12,77 \mathrm{~b}$ & $14,27 \mathrm{ab}$ & $18,86 \mathrm{a}$ \\
\hline
\end{tabular}

a - $d$ : Effet significatif du génotype pour un paramètre donné avec $P<0,05$.

Tableau 14. Effet du génotype et du gavage sur l'appréciation sensorielle de filets grillés de canards âgés de 14 semaines (l'intensité du critère mesuré est croissante avec la note ; $G$ = gavés, $T=$ témoins, moyenne $\pm E T$ ).

\begin{tabular}{|c|c|c|c|c|c|c|c|}
\hline \multicolumn{2}{|c|}{ Paramètres } & $\mathrm{n}$ & Tendreté & Jutosité & Fibreux & Flaveur globale & Flaveur canard \\
\hline \multirow[t]{2}{*}{ Pékin } & G & 11 & $5,32 \pm 1,25 a b$ & $4,33 \pm 1,04 a b c$ & $3,78 \pm 1,37 b c$ & $4,59 \pm 1,15 a b$ & $5,13 \pm 1,11 \mathrm{ab}$ \\
\hline & $\mathrm{T}$ & 20 & $5,51 \pm 1,23 a$ & $4,52 \pm 1,01 \mathrm{a}$ & $3,67 \pm 1,42 c$ & $4,45 \pm 1,33 b$ & $4,97 \pm 1,26 a b$ \\
\hline \multirow[t]{2}{*}{ Mulard } & $G$ & 21 & $4,80 \pm 1,17 \mathrm{c}$ & $4,19 \pm 1,14 b c$ & $4,19 \pm 1,55 a b$ & $4,69 \pm 1,24 a b$ & $5,11 \pm 1,17 a b$ \\
\hline & $T$ & 20 & $4,72 \pm 1,21 \mathrm{~cd}$ & $4,26 \pm 1,09 a b c$ & $4,17 \pm 1,49 a b$ & $4,47 \pm 1,23 b$ & $4,96 \pm 1,17 a b$ \\
\hline \multirow[t]{2}{*}{ Hinny } & G & 21 & $4,99 \pm 1,18 b c$ & $4,26 \pm 1,00 a b c$ & $3,99 \pm 1,4 a b c$ & $4,83 \pm 1,24 a$ & $5,25 \pm 1,17 a$ \\
\hline & $T$ & 20 & $4,89 \pm 1,24 b c$ & $4,39 \pm 1,01 a b$ & $4,12 \pm 1,48 a b$ & $4,55 \pm 1,28 a b$ & $5,07 \pm 1,16 a b$ \\
\hline \multirow[t]{2}{*}{ Barbarie } & $G$ & 15 & $4,39 \pm 1,17 \mathrm{~d}$ & $3,95 \pm 1,14 \mathrm{c}$ & $4,33 \pm 1,47 a$ & $4,54 \pm 1,26 a b$ & $4,93 \pm 1,25 a b$ \\
\hline & $T$ & 17 & $4,38 \pm 1,18 d$ & $4,28 \pm 1,21 a b c$ & $4,36 \pm 1,47 a$ & $4,35 \pm 1,27 b$ & $4,83 \pm 1,17 b$ \\
\hline \multicolumn{3}{|c|}{ Effet génotype } & $* * *$ & $* * *$ & $* * *$ & * & * \\
\hline \multicolumn{3}{|c|}{ Effet gavage } & ns & $* * *$ & ns & $\star * *$ & $* *$ \\
\hline \multicolumn{3}{|c|}{ Interaction } & $* * * *$ & $* * \star$ & $* * *$ & $* *$ & * \\
\hline
\end{tabular}

${ }^{*} * * * * *$ : Effet significatif à $\mathrm{P}<0,05, \mathrm{P}<0,01$ ou $\mathrm{P}<0,001-\mathrm{ns}=$ non significatif.

$a-d$ : Différences significatives entre lots. $n s=$ non significatif. 
lipides plus faible, une quantité de collagène plus importante, une solubilité du collagène moindre (tableau 15, Larzul et al 2002) et un diamètre des fibres plus important (Chartrin et al 2004). Enfin, le génotype a peu ou pas d'effet sur l'évolution du $\mathrm{pH}$ postmortem dans les magrets (Larzul et al 2002). Chez le poulet, la sélection divergente sur la quantité de gras abdominal n'a pas eu d'effet ni sur la teneur en lipides du filet ni sur sa qualité organoleptique (Ricard et al 1983). Il faut remarquer également que dans ces deux lignées, les poids de muscle sont équivalents. La qualité sensorielle de la viande des oies landaises et polonaises n’a pas été évaluée. Cela aurait été intéressant car dans ce cas la teneur en lipides est équivalente dans les filets des deux races alors que le poids du filet est supérieur chez les oies polonaises.

\section{Conclusion}

Par analogie avec les observations réalisées chez des poulets sélectionnés de façon divergente sur la quantité de gras abdominal, le canard de Barbarie nourri à volonté et comparé à âge commercial égal avec le canard Pékin semble avoir un métabolisme plutôt orienté vers la croissance musculaire et donc la synthèse de protéines et une activité de lipogénèse hépatique inférieure ce qui expliquerait leur engraissement moindre. Il serait intéressant de refaire les comparaisons présentées dans cette synthèse avec des canards de Barbarie plus âgés que les canards Pékin de deux voire quatre semaines. Il faudrait également valider l'hypothèse sur le métabolisme protéique, par l'évaluation d'un ou plusieurs marqueurs spécifiques comme par exemple le rapport ARN totaux/protéines totales dans le muscle. Par contre, lorsqu'il est gavé, le canard de Barbarie est capable d'utiliser très efficacement les nutriments pour la synthèse des lipides. Il présente alors une meilleure aptitude à la stéatose hépatique que le canard Pékin qui présente un engraissement périphérique au niveau des tissus adipeux et musculaires plus important. En effet, la lipogénèse hépatique est plus efficace chez le canard de Barbarie. Par contre, sa capa- cité à exporter les lipides hépatiques est inférieure. Par ailleurs, l'activité de la lipoprotéine lipase est également plus faible chez le canard de Barbarie, en particulier en fin de gavage, ce qui favorise le retour des triglycérides sanguins vers le foie. Les canards hinnies et mulards présentent toujours des valeurs intermédiaires à celles des espèces parentales pour l'ensemble de ces paramètres à l'exception de la capacité d’ingestion pour lesquels ils bénéficient d'un effet d'hétérosis. Cette aptitude leur permet de produire un foie gras équivalent voire plus important que celui du canard de Barbarie et la qualité technologique de leur foie est supérieure. Ces différents éléments sont synthétisés dans la figure 3 . Les différences entre génotypes de canard dans l'accumulation des lipides intramusculaires, exacerbées par le gavage, ont également des conséquences sur la qualité nutritionnelle et sensorielle de la viande et probablement sur l'aptitude à la conservation des produits frais, congelés et/ou transformés (filets et magrets séchés ou fumés) ce qui reste à explorer.

\section{Références}

Alleman F., Bordas A., Caffin J.P., Daval S., Diot C., Douaire M., Fraslin J.M., Lagarrigue S., Leclercq B., 1999. L'engraissement chez le poulet : aspects métaboliques et génétiques. INRA Prod. Anim., 17 (4), 265-273.

Baéza E., Dessay C., Wacrenier N., Marché G., Listrat A., 2002. Effect of selection for improved body weight and composition on muscle and meat characteristics in Muscovy duck. Brit. Poult. Sci., 43, 560-568.

Berri C. Wacrenier N., Millet N., LebihanDuval E., 2001. Effect of selection for improved body composition on muscle and meat characteristics of broilers from experimental and commercial lines. Poult. Sci., 80, 833-838.

Chartrin P., Mourot J., Bernadet M.D., Guy G., Duclos M.J., Baéza E., 2003. Effect of genotype and force feeding on the intramuscular fat deposition in duck. XVI ${ }^{\text {th }}$ European Symposium on the Quality of Poultry Meat, St Brieuc, France, 23-26 sept. 2003, 224-230.

Chartrin P., Schiavone A., Bernadet M.D., Guy G., Mourot J., Duclos M.J., Baéza E., 2004. Effet du génotype et du gavage sur les dépôts de lipides intramusculaires dans le filet de canard. 6e Journées de la Recherche sur les Palmipèdes à Foie Gras, Arcachon, France, 7-8 oct 2003, 4952.

Constans T., Chevalier B., Derouet M., Simon J., 1991. Insulin sensitivity and liver insulin receptor structure in ducks from two genera. Am. J. Physiol., 261, R882-R890.

Davail S., Guy G., André J.M., Hermier D., Hoo-Paris R., 2000. Metabolism in two breeds of geese with moderate or large overfeeding induced liver-steatosis. Comp. Biochem. Physiol. Part A, 126, 91-99.

Davail S., Rideau N., Guy G., André J.M. Hermier D., Hoo-Paris R., 2003. Hormonal and metaboic responses to overfeeding in three genotypes of ducks. Comp. Biochem. Physiol. Part A 134 (4), 707-715.

Fournier E., Peresson R., Guy G., Hermier D., 1997. Relationships between storage and secretion of hepatic lipids in two breeds of geese with different susceptibility to liver steatosis. Poult. Sci., 76, 599-607.

Guy G., Rousselot-Pailley D., Gourichon D., 1995. Comparaison des perfomances de l'oie, du canard mulard et du canard de Barbarie soumis au gavage. Ann. Zootech. 44, 297-305.

Guy G., Hermier D., Davail S., Bely M., André J.M., Hoo-Paris R., 1999. Meat production and force-feeding ability of different types of ducks. $1^{\text {st }}$ World Waterfowl Conference, Taichung, Taïwan, 1-4 déc. 1999, 462-468.

Hermier D., Saadoun A., Salichon M.R., Sellier N., Rousselot-Pailley D., Chapman M.J., 1991. Plasma lipoproteins and liver lipids in two breeds of geese with different susceptibility to hepatic steatosis: changes induced by development and force-feeding. Lipids, 26 (5), 331-339.

Hermier D., 1997. Lipoprotein metabolism and fattening in poultry. J. Nutr., 127, 8055 8085.

Hermier D., Salichon M.R., Guy G., Peresson R., Mourot J., Lagarrigue S., 1999a. La stéatose hépatique des palmipèdes gavés : bases métaboliques et sensibilité génétique. INRA Prod. Anim., 12 (4), 265-271.

Hermier D., Salichon M.R., Guy G., Peresson R., 1999b. Differential channelling of liver lipids in relation to susceptibility to hepatic steatosis in the goose. Poult. Sci.., 78, 13981406.

Hermier D., Guy G., Guillaumin S., 2000. Bases métaboliques de la sensibilité à la stéatose hépatique du canard. 4e Journées de la Recherche sur les Palmipèdes à Foie Gras, Arcachon, France, 4-5 oct. 2000, 55-58.

Hermier D., Guy G., Guillaumin S, Davail S., André J.M., Hoo-Paris R., 2003. Differential channelling of liver lipids in relation to susceptibility to heaptic steatosis in two species of ducks. Comp. Biochem. Physiol., Part B, 135, 663-675.

Klasing K.C., 1998. Lipids in: Comparative Avian Nutrition, CAB International, Davis, USA, 171-200.

Larzul C., Imbert B., Bernadet M.D., Guy G., Rémignon H., 2002. Qualité du magret dans un croisement factoriel Barbarie X Inra 44. $5^{e}$ journées de la Recherche sur les Palmipèdes à Foie Gras, Pau, France, 9-10 oct. 2002, 29-32.

Mourot J., Guy G., Lagarrigue S., Peiniau P., Hermier D., 2000. Role of hepatic lipogenesis in the susceptibility to fatty liver in the goose (Anser anser). Comp. Biochem. Physiol. Part B, 126, 81-87. 
OFIVAL 2004. Le marché des produits carnés et avicoles en 2003 (France-UE-Monde), 450 pp.

Retailleau B., 1999. Comparison of the growth and body composition of 3 types of ducks: Pekin, muscovy and mule. $1^{\text {st }}$ World Waterfowl Conference, Taichung, Taïwan, 1-4 déc. 1999, 597-602.
Ricard F.H., Leclercq B., Touraille C., 1983. Selecting broiler for low or high abdominal fat: distribution of carcass fat and quality of meat. Br. Poult. Sci., 24, 511-516.

Ricard F.H., 1986. Composition anatomique de la carcasse du canard mulard comparé aux deux types parentaux. Comptes rendus de la
Conférence Avicole WPSA-SIMAVIP, Cahier $n^{\circ} 3,47-64$.

Salichon M.R., Guy G., Rousselot-Pailley D., Blum J.C., 1994. Composition des trois types de foie gras : oie, canard mulard et canard de Barbarie. Ann Zootech., 43, 213-220.

\section{Résumé}

Le canard de Barbarie présente une meilleure aptitude à la stéatose hépatique que le canard Pékin qui présente un engraissement périphérique au niveau des tissus adipeux et musculaires plus important. En effet, la lipogénèse hépatique est plus efficace chez le canard de Barbarie. Par contre, sa capacité à exporter les lipides hépatiques est inférieure. Par ailleurs, l’activité de la lipoprotéine lipase est également plus faible chez le canard de Barbarie, en particulier en fin de gavage, ce qui favorise le retour des triglycérides sanguins vers le foie. Les canards hybrides, hinnies et mulards présentent toujours des valeurs intermédiaires à celles des espèces parentales pour l'ensemble de ces paramètres à l'exception de la capacité d'ingestion et du poids du foie gras pour lesquels ils bénéficient d'un effet d'hétérosis.

\section{Abstract}

The fattening ability of Muscovy, Pekin and their hybrids, hinny and mule ducks

The Muscovy duck has a higher susceptibility to hepatic steatosis than the Pekin duck which exhibits a higher fattiness in adipose and muscle tissues. Currently, the Muscovy duck has a more efficient hepatic lipogenesis but its ability to export lipids is lower. Moreover, the activity of lipoprotein lipase is also lower in the Muscovy duck, particularly at the end of the overfeeding period, which enhances the return of circulating triglycerides to the liver. In comparison with the parental species, the hinny and mule ducks always present intermediate values for all these parameters except for feed ingestion capacity and fatty liver weight for which they benefit from a heterosis effect.

E. BAEZA, N. RIDEAU, P. CHARTRIN, S. DAVAIL, R. HOO-PARIS, J. MOUROT, G. GUY, M.D. BERNADET, D. HERMIER, 2005. Canards de Barbarie, Pékin et leurs hybrides : aptitude à l'engraissement. INRA Prod. Anim., 18, 131141. 
